\title{
Interactive comment on "Intercomparison and Evaluation of Ground- and Satellite-Based Stratospheric Ozone and Temperature profiles above Observatoire Haute Provence during the Lidar Validation NDACC Experiment (LAVANDE)", by Robin Wing et al.
}

\section{Anonymous Referee \#2}

Received and published: 19 June 2020

Review of "Intercomparison and Evaluation of Ground- and Satellite-Based Stratospheric Ozone and Temperature profiles above Observatoire Haute Provence during the Lidar Validation NDACC Experiment (LAVANDE)" by Wing et al.

The study presents a detailed comparison of the stationary lidars at OHP with a series of other data sets, in particular a mobile lidar system from NASA. Also ECC, MLS, SABER ozone and temperature profiles are considered. The comparison has been 
performed "blind" by an impartial expert, which is a very interesting approach. For the comparison, a wide range of visualizations is presented reaching from mean profiles, over time series and scatter plots to correlation profiles. This gives a detailed insight in the behavior of each data set but makes the paper a bit lengthy. The study also evaluates in detail the uncertainties of each data set, which is a very interesting aspect and should be done more in validation studies.

Interactive

comment

Validations studies such as the one presented here are important contributions to understand instrumental differences and to obtain consistent long term data sets. Methods and results are well explained and the paper follows a logic structure.

I recommend the paper for publication in AMT and provide below minor comments for the authors to consider.

\section{Minor comments}

In the effort to identify co-located profiles between lidar and satellite the authors allow a time difference of up to 12 hours. Given the diurnal cycles in temperature and ozone in the stratosphere and mesosphere, this seems too tolerant. Have any effects related to tides and diurnal cycles been corrected? An analysis of the distribution of the time differences would be helpful to convince the reader that systematic biases are not a consequences of diurnal cycles.

The weighted mean on p6, I16 takes into account the typical wind speed in the stratosphere. What is the justification for this? Diurnal cycles in temperature and ozone are not driven by advection but by photochemistry and tidal waves. Please comment.

P6, 111: do you mean 10 to 20 matching profiles per night? With the chosen wording this is not absolutely clear.

Interactive comment on Atmos. Meas. Tech. Discuss., doi:10.5194/amt-2020-9, 2020. 